\title{
Ethical Consumption Practices: \\ Co-Production of Self-Expression and Social Recognition
}

\author{
Author and Contact \\ Dr. Hélène Cherrier * \\ Room 529 \\ H69 - Economics and Business Building \\ The University of Sydney \\ NSW 2006 Australia \\ E-Mail: h.cherrier@econ.usyd.edu.au \\ Phone: +61 29036 6420; Fax: +61 293516732
}

* Hélène Cherrier (Ph.D. University of Arkansas) is currently a lecturer at the University of Sydney, Australia. Her research interests embrace radical changes in consumption lifestyles; social and environmental activism;

appropriation and reconfiguration of consumer meanings, symbols, and usage; identity politics; and the role of consumption in identity construction. 


\begin{abstract}
Abstract

Ethical considerations regularly demand references to the moral climate, which, as a form of grand narrative or regime of truth, provides direction for choices between right and wrong, good and bad, ethical and unethical. Yet from a postmodern perspective, the moral climate has scattered into countless narratives, such that what is good or ethical may no longer be certain everywhere and in every situation. In a postmodern world, no essential grand narrative, regime of truth, or foundational ethical direction exists, because the self has been rendered free and autonomous from traditional values. As an independent agent, the postmodern self confronts a plethora of possibilities. Although the confrontation of multiple narratives appears in radical postmodern theory as saturating and disorienting, this article posits that clear signs of ethical directions within postmodern pluralism remain.
\end{abstract}




\section{Introduction}

Ethical considerations regularly demand references to the overall moral climate. As a form of grand narrative or "regime of truth" (Butler, 2005), the moral climate directs consumer choices between right and wrong, good and bad, ethical and unethical. However, postmodernism has fragmented the ethical climate. Best and Kellner (2001, p. 277) note that the postmodernist ethic involves "ethics of difference, contingency, and nonfoundationalism" that recognize change and indeterminacy as prominent aspects of the world. In a constantly changing and unpredictable world, postmodern ethics, rather than being fixed and predetermined, become plural and nonlinear. For example, increasing virtual and physical access to product (e.g., point-of-sale and non-point-of-sale information) and background (e.g., broad ethical issues) data expose consumers to a diversity of opinions, attitudes, and ethical stands (Berry and McEachern, 2005). Buying second-hand items, an electric car, or even common items such as coffee, tea, cereal, bread, or trash bags carries a plurality of ethical stances that range from environmentalism to solidarity to fair trade to health to community support. In addition, postmodern ethics has become a topic of discussion among scientists from conflicting fields, governments with a variety of interests, competing ethical consumer publications, informal communication networks, and the private sector. As a consequence, advertising, news reports, and expert columns often provide conflicting and nonlinear ethical opinions about what to purchase (or not purchase). There cannot be, for example, a regime of truth about recycling when scientists disagree on the evidence, country representatives disagree on the outcomes, and commentators' opinions change continuously (Volokh and Scarlett, 1997). This increasing range and variability of ethical perspectives on any condition has led to what Beck (1999, p. 131) calls "our inability to know." The pluralization of expert systems and greater access to information prompts multiple and often 
contradictory opinions about the "what" and "how" of ethical consumption (Beck, 1999), such that what seems good or ethical for one may not be so for another. In a postmodern world, there is no essential grand narrative, regime of truth, or foundational ethical direction (Gergen, 1991), so for the postmodern consumer, truth, morality, and ethics apply solely to the individual.

Although some theorists view the absence of a unifying grand narrative as troublesome, others celebrate the resultant potential for self-expression, self-discovery, and self-construction (Firat and Venkatesh, 1995). Liberated from the normative gaze of society and institutions, postmodern consumers can acquire, consume, and dispose of ethical objects/services/practices that reflect who they are and who they want to be (Belk, 1988). They might refuse to purchase cheap items made in sweatshops to express their concerns about workforce exploitation, ride a bicycle to preserve the ozone layer, stop using chemical-laden toiletries tested on animals to protest animal cruelty, and purchase fair-trade coffee and organic vegetables to support environmental sustainability and human rights. Likewise, they can leave their high-paying job to experience a simpler lifestyle or move to the countryside to exist away from urban pollution and overpopulated suburbs. The act of choosing among this wide constellation of possibilities calls for active participation in defining and selecting ethical products, ethical organizations, and, ultimately, ethical consumption patterns. By becoming active participants in the working of their ethical consumption lifestyles, consumers critically analyze their personal ethical concerns and self-concepts, which initiates customized perceptions and personalized practices of the "good life" and the common good. As Zavestoski (2002) notes, the process of self-inquiry leads to the framing and shaping of anti-consumption attitudes, such that the process of self-inquiry represents a rational response to a general feeling of dissatisfaction with life. In this sense, self- 
inquiry ultimately enables an authentic self through active and deliberate choices of a specific, ethical consumption lifestyle (Sen, 1987; Zavestoski, 2002).

Although the process of self-inquiry is an important element in defining a specific consumption lifestyle, this article argues it is not a unilateral influence. To place the question of self-inquiry at the pivotal center of ethical consumption practices embodies an idealistic, neoliberal notion of the consumer (Shankar et al., 2006). According to a neoliberal perspective, consumers question their existence and reshape their lives by exercising their freedom to choose ethical consumption practices in the marketplace. Thus, the neoliberal self is a knowledgeable, integrated, rational subject who actively and deliberately acquires, consumes, and disposes of ethical objects that symbolize its (desired) identities. The ethical consumer self-creates through will, operates freely in its own construction, and consciously chooses elements in the marketplace that meet its need for a meaningful or authentic identity. Implicit in this liberal view is the idea that ethical consumers are knowledge-grounded subjects who make rational choices to maximize their interests and their quest for identity. But this conception of ethical consumers as rational choosers shows little resemblance to ethical individuals in the real world. That is, actual pluralistic, heterogeneous, multiskilled ethical persons get reduced to utilitarian, rational individuals who use ethical consumption practices in pursuit of their identity goal.

There are three main problems with this neoliberal notion of the consumer in the context of ethical consumption practices. First, a neoliberal perspective assumes that ethical consumers have the capacity to make consumption decisions through their understanding of ethical implications and thus emphasizes internal reflexivity and grounded knowledge. But the postmodern world provides an incommensurable amount of information about ethical issues and practices; Berry and McEachern (2005) identify 24 national eco-label schemes worldwide and 
more than 17 different English-language Web sites that provide information for ethical consumers. Although informative and necessary, ethical information about commercial strategies, ecological impacts, animal welfare, workers' rights, and genetic engineering is complex and can overwhelm, disorient, or even saturate consumers (Berry and McEachern, 2005; Gergen, 1991). Furthermore, the spread of ethical information about products, services, or corporations provokes recognition of a broad cause-and-effect chain and an increasing need to choose among a wide variety of options. This choice can be liberating but also can burden consumers and create moral fatigue, which in turn paralyzes and immobilizes them (Mick et al., 2004; Shankar et al., 2006).

Second, neoliberal consumers have the freedom and autonomy to promote ethical aspects of their identity through personalized choices in the marketplace; thus, neoliberal theory accentuates such choices as part of the good life. It imagines that people coalesce their multiple identities into a united and desired ethical identity by choosing when and how to participate in ethical practices. However, an ethical consumption experience goes beyond an individual act in the marketplace. As Carù and Cova (2003) note, the experience of consumption is not solely an individual experience but rather a social one. Consuming ethically links consumers to family members, friends, the state, and the market. Thus, consumers' degree of ethical involvement depends not only on their particular aims and personal (desired) identity but also on their cultural background, personal histories, commitment to others' needs, and overall social context. As Shaw et al. (2006, p. 1062) note, ethical consumers often articulate their behavior as part of “collective participation."

Third, emphasizing self-inquiry to explain the burgeoning ranks of ethical consumers stresses idealistic, rational identity-construction processes. But consumers rarely are deliberate, 
rational, and calculative enough to become meticulous economic agents or scientifically based ethical selves. Consumer identity formation, even in a postmodern world, exhibits societal influences, a reliance on opinion leaders, and shared identifications (Cherrier and Murray, 2007). For example, social influences from religious movements or self-help group therapies provide partial, multiple, yet noticeable ethical stands that orient participants. The ability to choose an ethical consumption lifestyle and identity therefore does not result purely from a process of selfinquiry.

In a world that offers plural and nonlinear ethical stands, making ethical choices must involve far more than just getting to know oneself. By investigating a countercultural movement called voluntary simplicity, this article demonstrates that the selection and creation of ethical consumption practices often get subordinated to societal formation processes. The key reference points for constructing ethical consumption lifestyles come from not only the inside (selfidentity) but also the outside (collective identity). This framework follows a co-productive, coconstructive approach to identity construction, developed in the field of new social movement theories. In the following sections, I provide a brief overview of new social movement theory, with an emphasis on the concept of identity as both individually and socially constructed. I then consider the voluntary simplicity movement using a dialectical perspective on identity construction. The conclusion provides a co-productive view of the construction of ethical consumption practices within postmodern pluralism.

\section{New Social Movement Perspectives on Identity}

During the second half of the twentieth century, European scholars noted the importance of diffuse, often apolitical social movements. To distinguish these movements from collective 
behavior, resource mobilization, or political processes, they considered the structural origin of protests within collective behavior (Della Porta and Diani, 1999) and specified social movements as products and subjects of deliberate action generated by members of what Alain Touraine (1977, 1981) calls "the self-production of society." According to this perspective, the new social movement relates to the experience of partisans and would-be partisans in ways that they define and that describe their interests, norms, and meanings (Gusfield et al., 1994). Touraine's typology of social movements includes three principles: the movement's identity, its adversary, and its vision or societal goal (Kozinets and Handelman, 2004; Touraine, 1977, 1981). Although theorists argue there is nothing new or unique in the new social movement's adversary or vision compared with other types of collective actions (Pichardo, 1997), its approach to identity construction as a dialectical process of the individual and the collective identity offers a valuable means to consider ethical consumption practices.

Specifically, the new social movement perspective shifts movements to an identitycentered paradigm (Touraine, 1981), which makes the construction of identity central rather than peripheral to the formation of the movement (see Table 1). The interactions among individuals construct their identities, such that out of an interaction process emerges a common cognitive framework that enables members to assess the environment in which they live (Melucci et al., 1989). This common framework then represents the collective identity.

\section{Table 1. Identity within New Social Movement Perspective}

\footnotetext{
New social movement as a "collective search for identity" defined by Gusfield et al. (1994)

1. New social movements tend to transcend class structure; youth, gender, sexual orientation, or professions do not correspond with structural explanations.

2. The ideological characteristics of the new social movements are not overarching ideologies but rather pluralistic values and ideas with pragmatic orientations.

3. The mobilizing factors tend to focus on cultural and symbolic issues that are linked with issues of identity rather than on economic grievances.

4. New social movements are more "acted out" in individual actions rather than through or among mobilized groups.

5. New social movements often involve personal and intimate aspects of human life, they extend into arenas of daily life: what we eat, wear, and enjoy; how we make love, cope with personal problems, or plan or shun careers.

6. New social movements are characterized by nonviolence and civil disobedience challenging dominant norms of conduct.
} 
7. The development of new social movement is related to the credibility crisis of the conventional channels for participation in Western democracies.

8. New social movements tend to be segmented, diffuse, and decentralized.

This collective identity is fluid and relational because it emerges from interactions of various audiences (participants, spectators, allies, opponents, news media, public authorities) (Polletta and LJasper, 2001) and is not forged from fixed categories, such as race or gender. Rather, a diverse and evolving flux of interactions generate, maintain, and adapt collective identity (Crossley, 2002; Gusfield et al., 1994); as Melucci et al. (1989, p. 34) stress, "collective identity is an interactive and shared definition." The interactional accomplishment of collective identity occurs in submerged (i.e., invisible to the public eye, occurs in everyday life, and consists of multiple persons with temporary, limited, and fragmented involvement) social networks, which provide a space for circular patterns of interaction between inner experiences and social experiences that influence each other (Melucci et al., 1989). However, the networking characteristic of the new social movements pertains to more than organizing activities or sharing information; submerged networks are the "actual producers and distributors of cultural codes" (Castells, 1997, p. 362) that provide the means to rethink and reestablish societies. As such, submerged networks act as cultural laboratories within society (Melucci et al., 1989) and open new social spaces for creative interactions. This process of social learning in turn acts as a nonrigid structural force (Eyerman and Jamison, 1991).

On the basis of this evolving cultural material, participants build new identities that redefine their position in society, which in turn gives rise to what Castells (1997) calls project identities. Project identities redefine a person's position within society, so the process of constructing an individual identity is quintessentially social and intrinsically relational (Cherrier and Murray, 2007; Mead, 1968). Alberto Melucci (1996b, p. 30) defines identity as "a relation 
which embraces both our ability to recognize ourselves and the possibility of being recognized by others." Therefore, a person's sense of self gets constructed in relation to others in terms of differences and similarities, without which people could not know who they were and would have no identity.

The issues of collective identity, submerged social networks, and project identity as reflected in new social movement theories lead Hetherington (1998) to compare the new social movement's identity-centered paradigm to views discussed within notions of neo-tribes, life politics, and sub-politics. These perspectives all involve shared identifications with others (Klandermans and Johnston, 1995).

In the following discussion, I consider new social movement theory in the context of voluntary simplicity. To account for this case study, I integrate popular and academic literature on voluntary simplicity, downshifting, simple living, living lightly, downsizing, simplifying, the co-housing movement, permaculture village, art and craft revivals, environmental conservation and recycling, anti-nuclear demonstrations, urban cooperatives, and consumer frugality. In addition, repeated online browsing of "The Voluntary Simplicity Network," "Center for a New American Dream," "The Pierce Simplicity Study," "Seeds of Simplicity," "New Horizons for Learning," “Cecile Andrews \& Simplicity Circles Projects,” and “The New Roadmap Foundation" continued over a period of five years. Finally, I engaged in non-participant observation over a period of four years through an online subscription to the "The Voluntary Simplicity Network." The following discussion briefly retraces the origin of the voluntary simplicity movement and its significance by emphasizing a dualistic (empirical and normative) approach. The remainder of the discussion considers the voluntary simplicity movement in light 
of the new social movement theory, which accepts both normative and empirical approaches to the phenomenon.

\section{Case Study: The Voluntary Simplicity Movement}

In contemporary Western society, the idea of living more simply by simplifying life, downshifting, decreasing material possessions, or resisting consumerism represents a life choice phenomenon. Used widely in ordinary conversation and writing, the idea of voluntary simplicity appears in terminologies such as living lightly, simple living, downsizing, simplifying, voluntary simplicity lifestyles, and the co-housing movement. Broadly, voluntary simplicity is a intentional choice to work less, want less, and spend less and be happier in the process (Pearce, 2001). It reflects a change in consumption lifestyles toward harmonious and purposeful living (Elgin, 1981), which aims ultimately for happiness and well-being (Kèustenmacher and Seiwert, 2004).

This concern about the purpose of life and the danger of material affluence goes back to the Greek philosophers Plato, Socrates, Diogenes, and Aristotle, who professed two vices, excess and deficiency, whose mean is virtue (Floyd and Kilbourne, 1996). In the Christian era, Aristotelian ethics and Catholics discouraged material possessions and spending money on the basis of religious beliefs. Material objects were viewed as belonging to God, and it was by God's grace and for God's ends that anyone possessed anything (Shi, 1985). The support for simple living thus was established through religious power, which imagined God as the only truth. Without going into too much detail on the historical development of voluntary simplicity, the 1970s mark the shift from a religious sense of simple living to a focus on ecological sensitivity. After the energy crisis, the movement gradually evolved into a type of virtuous lifestyle (Shi, 1985; Sider, 1982). During this period, Elgin (1981) defined voluntary simplicity as “a 
singleness of purpose, sincerity and honesty within, as well as avoidance of exterior clutter, of many possessions irrelevant to the chief purpose of life." Voluntary simplicity thus means adopting a simpler lifestyle by reducing consumption and the hours spent working, which decreases stress; increases the time spent with children, friends, and family or contributing to the community; and enhances well-being. This definition involves voluntary simplicity in both inner and outer conditions of life, because it is both dedicated to externally imposed conditions, such as ecological collapse and societal control, and invokes a transcendental appeal to express an internally identified self. It demands abandonment of the love of money, the craving for possessions, and the prison of activities but not necessarily making money or the accumulation of things (Shi, 1985).

In 1998, Etzioni identified voluntary simplicity as an emergent social trend, and six years later, Grigsby (2004) noted that voluntary simplicity had shifted to a cultural movement that had created a group consciousness about the negative aspects of consumerism. The expansion of the voluntary simplicity movement also is reflected in social studies. Paul Ray (1997, p. 29) estimates that 24 percent of the U.S. adult population (44 million people) is disenchanted with the idea "of owning more stuff," and in a 1995 survey of 800 people, the Merck Family Fund Institute found $28 \%$ had cut back on their incomes during the past five years to reflect changes in their priorities, whereas $35 \%$ had increased their incomes. In the same survey, $82 \%$ of respondents agreed that "we buy and consume far more than we need," and 88\% agreed that "protecting the environment will require most of us to make major changes in the way we live" (Schwarz and Schwartz, 1998). Similarly, in 1995, the Trends Research declared simplifying life as "one of the top trends of the nineties" (cited in Schwarz and Schwarz, 1998). Then in 1998, Gerald Celente declared the new millennial trend to be grounded in simpler living lifestyles, and 
Juliet Schor noted that simple living had become a mainstream phenomenon (Schor, 1998, 1999, 2000; Schor and Holt, 2000). By 2005, 25 Internet sites, 12 English publications, and 50 institutions in Canada, the Netherlands, the United Kingdom, and the United States promoted the philosophies, ethics, and methods of a simplified life.

Although the voluntary simplicity movement appears to be a growing consumer practice, a review of related literature reveals its ambiguous ethical stance (Grigsby, 2004). For some authors, voluntary simplicity represents a disengagement from consumerism as a way to elevate inner expression, self-conception, and spirituality (Hunter, 2000). In this sense, voluntary simplifiers freely delineate their ethical stance on the basis of their personal motivations, experiences, and aspirations. Studying voluntary simplicity therefore would require an empirical understanding of consumers who reflexively move toward a simpler lifestyle. However, for other authors, voluntary simplicity relates to external forces such as environmental and social concerns (Dorf, 2001; Shama, 1981, 1985; Shama and Wisenblit, 1984a, 1984b), a lack of communal bonds (Sider 1982), or debt enslavement among the middle class (Schor, 1998, 2000), so the growth of voluntary simplicity reflects a response to living in a risky society (Beck, 1999), surrounded by environmental uncertainty, social inequalities, work overload, and/or societal constraints. According to this view, voluntary simplicity represents a normative phenomenon that can teach people how to live a sustainable consumption lifestyle and be happy in the process. Together, these empirical and normative approaches emphasize the ethical ambiguity of the voluntary simplicity movement, because the motivations, ideologies, and concerns of voluntary simplifiers involve human, religious, personal, and environmental positions, and their manifestations encompass consuming (or not) physical goods, services, events, ideas, people, 
organizations, or retail outlets. In the following sections, I use new social movement theory to explore the complexity of voluntary simplicity's ethical stance and direction.

\section{Voluntary Simplicity According to New Social Movement Theory}

Voluntary simplicity embodies a social movement because it connects different members of a society through a similar arena of interests, norms, personal meanings, or values. The common thread among members is their recognition that the values of consumer culture are at stake (Schor, 1998). They no longer find the taken-for-granted Western value of "more stuff is better" fulfilling. The concept of voluntary simplicity therefore deconstructs the dominant values and normative codes of consumer culture and reaffirms other basic values, such as humanity, community, locality, and respect for life and nature (Elgin, 1981). This approach is consistent with the notion of social movements that exist only when members of a society share the recognition that specific rules can no longer be taken for granted (Gusfield et al., 1994). In addition, voluntary simplicity conforms to new social movement theory because it expresses multiple values and reflects issues of project and collective identities.

\section{Pluralism of Ideas and Values}

For voluntary simplifiers, well-being comes not from accepting the default option but rather from making a decision to live with less. They adopt this disengagement from the default option in response to particular ideas and values rather than economic constraints (LeonardBarton, 1981). Such disengagement requires conscious and principled decisions that diverge from the process of capitalist accumulation (Floyd and Kilbourne, 1996). Therefore, voluntary 
simplifiers intentionally choose to exclude material goals and pursue a simple lifestyle oriented toward postmaterialistic values.

Although voluntary simplifiers share a goal and conscious decision to commit to the nonmaterial aspects of life, the means to achieve this goal are multiple (Huneke, 2005; Shaw and Newholm, 2002; Shaw et al., 2006) and often inconsistent (McDonald et al., 2006). Unlike Marxist considerations of a class-based political movement with a unifying ideology to guide decisions, the voluntary simplicity movement lacks a clear ideological, economic, ethnic, ecological, or social class focus. Instead, the philosophy encompasses moderation, selfdiscipline, care of mind and body, and spiritual growth "involving both inner and outer conditions" (Elgin, 1981); its process requires paring down to the essentials of life, determining what is important to a person, and confronting preestablished values.

This pluralism of values and considerations leads to diverse voluntary simplicity behaviors. Real life examples depicted in voluntary simplicity literature exemplify behavioral changes ranging from leaving a stressful job to moving away from an urban lifestyle, selling a car to ride a bicycle, decluttering a home, or even boycotting particular items or organizations. Such diversity is explicit in Duane Elgin and Arnold Mitchell's (1977) survey, which identifies five behavioral dimensions: material simplicity (buying and consuming less or only what one needs rather than overconsuming or catering to wants); self-determination (more control over one's life and less dependence on organizations); ecological awareness (recognition that people and matter are interdependent); human scale ("small is beautiful," or a preference for smaller, more efficient products and institutions); and personal growth (preference for inner psychological and spiritual development over economic development). 
The variety of deliberate actions generated by voluntarily simplifiers' particular values and interests lead to a diffuse, fluid, decentered, and apolitical social movement (Della Porta and Diani, 1999) that denotes the pluralism of ideas, values, and issues of individual and collective identities. Thus, this movement within consumer culture conforms to the definition of a new social movement advanced by Gusfield et al. (1994). Namely, new social movements exhibit a pluralism of ideas and values and tend to have pragmatic orientations (Gusfield et al., 1994). Although diverse and multiple, each value and idea expressed by the voluntary simplicity movement emerges in relation to cleavages that are either new, such as road rage or genetically modified food, or have received new content, such as individual expression.

\section{Individual Identities}

By drawing on actions that relate to daily life, such as working less, spending less, and consuming less, voluntary simplicity detaches itself from traditional models of political organization. It is less about institutional change than expressive actions relevant to personal beliefs, and the underlying values and beliefs that motivate "a commitment to the nonmaterial aspect of life" rely on a sense of rising consciousness about what provides meaning in life (Etzioni, 1998).

Shama (1981) argues that voluntary simplicity is a predictable consumer response to difficult and uncertain times. For example, contemporary societies face global, ecological, and social awareness challenges that compel consumption shifts (Floyd and Kilbourne, 1996; Shama, 1981). Externally imposed conditions influence internal self-regulation (Floyd and Kilbourne, 1996), but the ecological or societal pressures toward a simpler lifestyle are not sufficient to influence a person to practice a simple living lifestyle. As Elgin (1981) notes, a voluntary 
decision results not from acts of necessity, whether economic, ecological, medical, or social, but from a process of personal reflection on harmonious, purposeful living. However, this personal reflection itself emerges from both external and internal considerations.

By reducing and controlling their consumption practices, voluntary simplifiers express their values, ideas, beliefs, and overall identities. In recognizing the quality of their life depends on their external identity, they consciously decide to assimilate their external identity with their internally identified self. Therefore, identity becomes an "identity bricolage": the identified self involves decomposing existing identities into their constituent components and recombining them into a new identity (Featherstone, 1995; Melucci, 1996b). Through reflection, voluntary simplifiers engage and experience the lifestyle that gives rise to their desired self and state of being. As such, the voluntary simplicity movement links to what new social movement theorists refer to as personal transformation (Melucci et al., 1989). By opting for less money, more free time, and less work, voluntary simplifiers reject the idea that the good life is found through high consumption levels.

In addition, by rejecting affluent consumption, the voluntary simplicity movement embeds within a specific meaning of consumption. Persons and groups that use the term voluntary simplicity to describe their activities often discuss consumption in terms of consumerism and conspicuous consumption. These terms make the practice of consuming mainly structural; that is, it results from a system of codes and cultural schemes that prompt people to increase their social status by displaying positional objects (Bourdieu, 1984). By resisting consumerism and conspicuous consumption, voluntary simplifiers express their shift away from dominant patterns of cultural meanings and changes in how they establish their identity space. They struggle against the dominant system of codes and cultural schemes that mandate high level 
consumption to create happiness. For them, restricted rather than extravagant consumption becomes the instrument of self-expression. Thus, voluntary simplicity does not represent just resistance to the material, when objects define the person, but rather involves an alternative way to express common interests and experiences through consumption. Voluntary simplifiers select, purchase, use, maintain, repair, and dispose of tangible objects that are symbolic of their uniqueness, personal qualities, values, and attributes. As such, voluntary simplifiers do not resist material differentiation or material stigmatization but rather constitute them.

\section{Collective Identities}

Although identity is a vital element of voluntary simplicity, the notion of identity does not emerge from an individual process of self-identification and therefore should not be regarded solely as individualistic. Voluntary simplicity contains the aspiration to differentiate oneself from the rest of the world and be recognized by it. Melucci et al. (1989) address the realization of identity through collective claiming, with which people claim their right to realize their personal identity. The voluntary simplicity movement provides a form of effectual solidarity that enables, through the diffusion of submerged networks, shared symbols and solidarity.

Voluntary simplicity's submerged networks mainly consist of new forms of communications that provide instantaneous, two-way interactions at low financial costs and unprecedented speed, such as print, voice, and visual connections. An online search for "voluntary simplicity" results in a wealth of pages and texts that describe the movement's ideas and values, include statements from involved individuals and groups, and provide images, videos, suggested methods for successful simple living, letters of support, articles on the phenomenon, and much more. The Web pages affiliated with organizations such as The 
Voluntary Linking Network, Center for a New American Dream, Pierce Simplicity Study, Seeds of Simplicity, New Horizons for Learning, Cecile Andrews \& Simplicity Circles Projects, and The New Roadmap Foundation contain several hundred links to other pages of involved groups. These virtual linkages, Web sites, e-mail conferences, and participant lists make it possible for people with different social and cultural identities to interact freely on the basis of their concerns, beliefs, and values. For example, The Simple Living Network posts a list of several thousand persons from all over the world who participate in simple living and want to share their experiences with others.

These voluntary simplicity virtual networks also provide a small degree of organizational structure, though because of the diversity of participants' values and engagements, the structure is rather fluid, loose, and averse to bureaucratization, centralization, or leadership. No conditions or fees limit participation in virtual discussions or voluntary simplicity group lists, which mirrors Tarrow's (1998) differentiation of old and new social movements. For him, the newness of the new social movement reflects lighter, more decentralized collectives, which gain logistical and financial advantages that formerly belonged only to bureaucratic organization because of their use of submerged networks. Voluntary simplicity's submerged networks create a feeling of belonging and solidarity for members and provide a space to develop and perform an expressive identity. The virtual interactions and discovery of common interests and experiences in turn become a source of empowerment for creating distinct consumption lifestyles.

Physical, face-to-face interactions complement virtual networks; collective identity within the voluntary simplicity movement gets reinforced by local discussion groups, conferences, and classes. This element is clearly important; a voluntary simplicity conference with a $\$ 65-270$ per person entry fee at the Open Center in SoHo drew more than 300 people to 
discuss subjects such as "Are We Possessed by Our Possessions?" and "Leading a Life of Integrity.” In fall semester 2000, the School of Continuing Education and Professional Studies at New York University even offered a course on voluntary simplicity.

In addition to virtual and physical interactions, the voluntary simplicity movement communicates using magazines and books. Publications such as YES! A Journal of Positive Futures tout topics such as "money—print your own," "cities of exuberances," and the "moment of the millennium." Numerous books on voluntary simplicity offer ideas and values associated with simplifying life. Amazon.com lists seven books with "voluntary simplicity" in the title, 26 books that match "living simply," and 326 books have the word "simplicity" in their titles. Although the appropriation of the movement for commercial success contradicts the aim of rejecting material consumption, it also provides a terrain for the recognition of difference. As I have noted, voluntary simplicity provides virtual and physical spaces in which persons can share their personal values and experiences. By facilitating the formation of new identities, these spaces establish categories of belonging and group identification. Thus, through commercialization and marketing of the movement's discursive practices, voluntary simplicity loses its marginal status. Books on voluntary simplicity sold by global corporations such as Borders allow participants and potential participants to affiliate with the movement without being marginalized or stigmatized as "tree huggers."

\section{Producing the Voluntary Simplicity Ethical Stance}

Understanding voluntary simplicity from the perspective of new social movement theory shows the interconnection between individual and collective identity in the performance of controlled consumption practices. Individual participants assess their daily lives and consciously 
decide to act to gain control and live on less. Although all members embrace this principle, voluntary simplifiers exemplify multiple values and beliefs, which grants recognition to plural, cross-cutting, and divided identities within a single movement. This very plurality triggers discussions, exchanges of ideas, and dialogues on possible ways of living simply through submerged networks, such as support groups, chat rooms, conferences, and classes. Whether virtual or face-to-face, discussions about the what, how, and why of simplifying provide a sense of group solidarity and collective claiming. Therefore, the voluntary simplicity movement represents a new type of protest characterized by a plurality of views, though all views share the feeling that something is fundamentally wrong with current corporate-driven societies. Voluntary simplicity's submerged networks also reconfigure a social system based on new modes of interaction across space, culture, and social class that employ informal organizational structures and shared interests. In addition, they characterize nonhierarchical, voluntary, reciprocal, and horizontal modes of exchange.

The recognition of individual differences and the expression of collective claiming embedded within voluntary simplicity create an international movement with its own identity, agenda, and ethical stance. The claim that the voluntary simplicity ethical stance gets constructed through submerged dialogue internal to the movement points to its necessary temporality. That is, voluntary simplicity's ethical stance is fluid and constantly being renegotiated. By participating in a simple living lifestyle, voluntary simplifiers express their values, ideas, beliefs, and overall evolving identities. Likewise, they participate in developing voluntary simplicity's collective claiming and ethical orientation. In this way, individual and collective identities mutually shape and are shaped by the voluntary simplicity movement. On the one hand, voluntary simplicity collective claiming emerges from its members' interactions; on the other 
hand, the formation of members' identity occurs through group solidarity activated through submerged networks. Being a voluntary simplifier is therefore a constant project, even if stereotypes about how to live simply seem fixed. In this view, voluntary simplicity does not represent a fixed ethical direction that negates materialism, consumption culture, or economic practices; rather, its discourse is incessantly socially constructed by participants, and it socially constructs the social world. In other words, the voluntary simplicity ethical stance is fluid and simultaneously constituted by and socially transforming identities.

This perspective emphasizes social interactions and recognition of differences in the construction of the movement's ethical orientation. To exist as a group; voluntary simplifiers must claim recognition for their differences, as well as the differences between them and the dominant consumer culture. Such recognition produces a culture that affirms voluntary simplicity and fluid ethical directions. Neither the voluntary simplifier's ethical interests nor the movement's ethical stance come first, so the struggle to achieve a desired "ethical" identity shapes the movement's ethics as much as the movement's ethics determine voluntary simplifiers' ethical identities. The point is that neither is fixed; they both are produced and altered through social interactions and the recognition of difference. This view relates closely to Melucci et al.'s (1989, p. 178) study on social movements, which asserts that the "recognition of diversity and a respect for individual differences opens the way to new definitions of autonomy and authenticity, and for the development of notions of community, toleration, and human solidarity that offer possibilities for mutual involvement." Therefore, recognition rests at the heart of developing ethical consumption practices and constructing ethical orientations. In varying degrees of ethical understanding and valuations, people may be more or less inclined to discuss ethical issues and consume ethically, but a crucial aspect of their ethical orientation development is their 
acceptance and recognition of differences in themselves and others. This process of recognizing and being recognized creates a sense of self and contributes to the formation of collective identity.

\section{Implications and Further Research}

The modern epoch contains a confusing plurality of values and choices (Gergen, 1991; Schwartz, 2004), which means many lifestyles and types of consumption can be ethically valid, depending on the values, concerns, knowledge, historical background, or social context. In a pluralistic and complex world, things that seem ethical to one person may not mirror the general stance on an issue. Is it possible, without surrendering to strict authoritarian rules, to find ethical principles and values that help consumers navigate the confusing landscape by developing a set of minimum common standards they can use to evaluate and measure different ways of living ethically?

This article uses the voluntary simplicity movement to illustrate the co-productive process of individual and collective identities in the development of ethical standards. The new social movement perspective on identity construction, collective identification, and socialization processes indicates that ethical directions exist; they are both a background on which ethical consumers operate and a product of social relations. Therefore, ethical consumption practices are neither a response to rigid and authoritarian rules imposed on persons nor a pure product of voluntary and rational consumers. Rather, they represent the conditions and outcomes of interactions between individual and collective identity. This view introduces the moral climate to a matter of human relations, so ethics becomes a floating reference that is socially organized and 
flexibly yet systematically constituted through a constant dialogue between the participants and the movement.

Using the new social movement approach to ethical consumption has several implications for marketing. First, the perspective shifts the ethical consumer away from a postmodern self, liberated from restrictions and autonomous enough to make choices in the marketplace to create its own existence and difference (Firat and Venkatesh, 1995). Rather than choosing ethical consumption practices as a work of art (Featherstone, 1991) in a quest for an authentic identity (Zavestoski, 2002), the ethical consumer shares emotions, passions, and lifestyles. Submerged networks enable these persons to express and share their evolving values and concerns, which gradually leads them to construct new and evolving cultural codes and symbols to reconsider their lifestyle and identity through communion with others. Therefore, further research should concentrate on the shared ethical concerns, passions, or emotions that cause many heterogeneous consumers to interact within submerged networks. Ascribing value to the shared emotions and social interactions might suggest a means to explore the role that social movements play in motivating particular consumption practices (Kozinets and Handelman, 2004). In addition, a better understanding of the development and evolution of submerged networks may provide societal marketers with tools to enhance ethical consumers' sense of collective action, which in turn can improve their feelings of sovereignty and power (Shaw et al., 2006).

Second, the new social movement perspective on individual and collective identity as mutually constituted offers a new level of sensitivity in considering the development of ethical consumer identities. What it means to be an ethical consumer does not exist in isolation but rather is defined within submerged networks through constant negotiations between participants and movements. The meanings ascribed to ethical consumer identity necessarily and inevitably 
connect with social relations and collective experiences, so researchers should never conceptualize ethical consumer identity as fixed (McDonald et al., 2006) and must treat it instead as constantly evolving through processes of identification and recognition. The best way to study ethical consumer identity is to observe how it forms gradually; considering identity as a construction, a process never completed, and always evolving offers an opportunity to learn about ethical consumers as consumers in transition (Cherrier and Murray, 2007).

Third, research into ethical consumption recently has called for further qualitative investigation into micro-situational encounters (McDonald et al., 2006), which requires studying ethical consumers at the micro-level of social interactions, practice allegiance, gangs, tribes, subcultures, and the new social movement. Studying tribes in France with regard to the context of in-line roller skaters (Cova, 2001) or those in Italy who belong to "My Nutella The Community" (Cova and Pace, 2006), consumer researchers have developed the concept of tribal marketing (Cova 1997; Cova and Cova 2002). This concept provides interesting insights into ways to nurture the socialization process, facilitate interactional communication, and develop activities for the members of the tribe, as well as an interesting methodological stance. Tribal marketing researchers use market-oriented ethnography or ethnomarketing (Cova, 2001; Cova and Cova, 2002; Cova and Pace, 2006), which might be exploited to gain a better understanding of unstable, heterogeneous, and contradictory ethical consumers. However, though tribal marketing offers a promising approach to study collective sentiments and identification, it cannot address all issues of identity construction within submerged networks. For example, tribal marketing fails to consider the importance of power struggles that occur in any social relations (Hetherington, 1998), especially in social interactions among heterogeneous consumers during identity negotiation processes (Dolan, 2002). As Dolan (2002, p. 171) argues, "power is not a 
possession of producers or consumers but emerges in their mutual relations." By overlooking the importance of power, tribal marketing can satisfy only an empirical approach to ethical consumption, that is, understanding the how and what of the ethical consumer. But ethical consumption practices demand study that encompasses both normative and empirical considerations. Several authors highlight the normative aspect of ethical consumption to promote ethical considerations for the well-being of future generations and the survival of the planet (Shaw et al., 2006). New social movement theory offers just such an empirical and normative approach to consumer behavior by emphasizing the importance of micro-situational encounters among individual members (Melucci, 1996a; Melucci et al., 1989) and the production and distribution of cultural codes within submerged networks that represent normative codes used to reimagine society (Castells 1997). 


\section{REFERENCE}

Beck, Ulrich (1999), World risk society. Polity Press: Malden, MA.

Belk, R. W. (1988), Possession and the extended self, Journal of Consumer Research, 15: 13968.

Berry, Hannah and Morven McEachern (2005), Informing ethical consumers, in The Ethical Consumer, Rob Harrison, Terry Newholm, and Deirdre Shaw, eds. Sage Publications: London.

Best, Steven and Douglas Kellner (2001), The postmodern adventure : science, technology and cultural studies at the Third Millennium. Routledge: London.

Bourdieu, Pierre (1984), Distinction : a social critique of the judgment of taste. Routledge \& Kegan Paul: London.

Butler, Judith (2005), Giving an account of oneself. Fordham University Press: New York.

Carù, Antonella and Bernard Cova (2003), Revisiting the consumption experience: A more humble but complete view of the concept. Marketing Theory, 3 (2): 267-86.

Castells, Manuel (1997), The power of identity. Blackwell: Malden, MA.

Celente, Gerald (1998), Trends 2000 : how to prepare for and profit from the changes of the 21 st century. Warner Books: New York.

Cherrier, Helene and Jeff B. Murray (2007), Reflexive dispossession and the self: constructing a processual theory of identity, Consumption, Markets \& Culture, 10 (1).

Cova, Bernard (1997), Community and consumption: towards a definition of the "linking value" of product or services, European Journal of Marketing, 31 (3): 297-311.

- (2001), Tribal aspects of postmodern consumption research: the case of French in-line roller skaters," Journal of Consumer Behaviour, 1 (1): 67-77.

and Veronique Cova (2002), Tribal marketing: the tribilisation of society and its impact on the conduct of marketing, European Journal of Marketing, 36 (5/6): 595-620.

and Stephano Pace (2006), Brand community of convenience products: new forms of customer empowerment - the case of "My Natella The Community", European Journal of Marketing, 40 (9/10): 1087-105.

Crossley, Nick (2002), Making sense of social movements. Open University Press: Buckingham. 
Della Porta, Donatella and Mario Diani (1999), Social movements: an introduction. Blackwell: Malden, MA.

Dolan, Paddy (2002), The sustainability of "sustainable consumption", Journal of Macromarketing, 22 (2): 170-81.

Dorf, Richard C. (2001), Technology, humans and society : toward a sustainable world. 1st ed. Academic Press: San Diego.

Elgin, Duane (1981), Voluntary simplicity: toward a way of life that is outwardly simple, inwardly rich, 1st ed. Morrow: New York.

and Arnold Mitchell (1977), Voluntary simplicity, The Co-Evolution Quarterly, (Summer): 5-18.

Etzioni, Amitai (1998), Voluntary simplicity: characterization, select psychological implications, and societal consequences, Journal of Economic Psychology, 19: 619-43.

Eyerman, Ron and Andrew Jamison (1991), Social movements : a cognitive approach. Pennsylvania State University Press: University Park.

Featherstone, Mike (1991), Consumer culture and postmodernism. Sage Publications: London and Newbury Park, CA.

- (1995), Undoing culture : globalization, postmodernism and identity. Sage Publications: London and Thousand Oaks, CA.

Firat, A. Fuat and Alladi Venkatesh (1995), Liberatory postmodernism and the reenchantment of consumption, Journal of Consumer Research, 22 (December): 239-60.

Floyd, R. W. and W.E. Kilbourne (1996), The meaning and morality of voluntary simplicity, history and hypothesis on deliberately denied materialism, in Consumption, Marketing, and Macrodimension, R. W. Belk, N. Shalakia, and A. Venkatesh, eds. The New Press: New York.

Gergen, Kenneth J. (1991), The saturated self : dilemmas of identity in contemporary life. Basic Books: New York.

Grigsby, Mary (2004), Buying time and getting by: the voluntary simplicity movement. State University of New York Press: Albany, NY.

Gusfield, Joseph R., Enrique Laraäna, and Hank Johnston (1994), New social movements : from ideology to identity. Temple University Press: Philadelphia, PA.

Hetherington, Kevin (1998), Expressions of identity: space, performance, politics. Sage Publications: London and Thousand Oaks, CA. 
Huneke, Mary E. (2005), The face of the un-consumer: an empirical examination of the practice of voluntary simplicity in the United States, Marketing and Psychology, 22 (7): 527-49.

Hunter, Jeremy H. (2000), A thematic summary of the positive psychology meetings: finding alternatives to materialism, The Quality of Life Research Center.

Kèustenmacher, Werner and Lothar Seiwert (2004), How to simplify your life : seven practical steps to letting go of your burdens and living a happier life. McGraw-Hill: New York.

Klandermans, Bert and Hank Johnston (1995), Social movements and culture. University of Minnesota Press: Minneapolis, MN.

Kozinets, Robert V. and Jay M. Handelman (2004), Adversaries of consumption: consumer movements, activism, and ideology, Journal of Consumer Research, 31 (December): 691-704.

Leonard-Barton, Dorothy (1981), Voluntary simplicity lifestyle and energy conservation, Journal of Consumer Research, 8 (December): 243-53.

McDonald, Seonaidh, Caroline J. Oates, William C. Young, and Kumju Hwang (2006), Toward sustainable consumption: researching voluntary simplifiers, Psychology \& Marketing, 23 (6): 515-34.

Mead, George Herbert (1968), George Herbert Mead; essays on his social philosophy. Teachers College Press: New York.

Melucci, Alberto (1996a), Challenging codes : collective action in the information age. Cambridge University Press: Cambridge.

(1996b), The playing self : person and meaning in a planetary society. Cambridge University Press: Cambridge.

- John Keane, and Paul Mier (1989), Nomads of the present: social movements and individual needs in contemporary society. Temple University Press: Philadelphia.

Mick, David Glen, Susan M. Broniarczyk, and Haidt Jonathan (2004), Choose, choose, choose, choose, choose, choose, choose: emerging and prospective research on the deleterious effects of living in consumer hyperchoice, Journal of Business Ethics, 52 (3): 207-11.

Pearce, Joseph (2001), Small is still beautiful. HarperCollins: London.

Pichardo, Nelson A. (1997), New social movements: a critical review, Annual Review of Sociology, 23: 411-30.

Polletta, Francesca and James M. LJasper (2001), Collective identity and social movements, Annual Review of Sociology, 27: 283-305. 
Ray, Paul H. (1997), The emerging culture, American Demographics, 19 (February): 28-32.

Schor, Juliet (1998), The overspent American : upscaling, downshifting, and the new consumer, 1st ed. Basic Books: New York.

New York.

(1999), The overspent American: why we want what we don't need. HarperPerennial:

- (2000), Toward a new politics of consumption, in The Consumer Society Reader, Juliet B. Schor and Douglas B. Holt, ed. The New Press: New York.

and Douglas B. Holt (2000), The consumer society reader. New Press: New York.

Schwartz, Barry (2004), The tyranny of choice, Scientific American, 290 (4): 70-76.

Schwarz, Walter and Dorothy Schwartz (1998), Living lightly, travels in post-consumer society. Jon Carpenter Publishing: United Kingdom.

Sen, Amartya Kumar (1987), On ethics and economics. Blackwell: Oxford.

Shama, Avraham (1981), Coping with stagflation: voluntary simplicity, Journal of Marketing, 45 (Summer): 120-34.

62.

(1985), The voluntary simplicity consumer, Journal of Consumer Marketing, 2 (4): 57-

and Joseph Wisenblit (1984a), Measuring voluntary simplicity values and lifestyle, World Future Society Bulletin 4, (July-August): 14-18.

and - (1984b), Values of voluntary simplicity: lifestyle and motivation,

Psychological Reports, 55, 231-40.

Shankar, Avi, Hélène Cherrier, and Robin Canniford (2006), Consumer Empowerment: A Foucauldian Interpretation, European Journal of Marketing.

Shaw, Deirdre and Terry Newholm (2002), Voluntary simplicity and the ethics of consumption, Psychology \& Marketing, 19 (2): 167-85.

- - $\longrightarrow$, and Roger Dickinson (2006), Consumption as voting: an exploration of consumer empowerment, European Journal of Marketing, 40 (9/10): 1049-67.

Shi, David E. (1985), The simple life: plain living and high thinking in American culture. Oxford University Press: New York.

Sider, R. J. (1982), Lifestyle in the Eighties: an evangelical commitment to simple lifestyle. Westminster John Knox Press: New York. 
Tarrow, Sidney G. (1998), Power in movement : social movements and contentious politics, $2 \mathrm{~d}$ ed. Cambridge University Press: Cambridge.

Touraine, Alain (1977), The self-production of society. University of Chicago Press: Chicago. (1981), The voice and the eye: an analysis of social movements. Cambridge University Press and Maison des sciences de l'homme: Cambridge and Paris.

Volokh, Alexander and Lynn Scarlett (1997), Is recycling good or bad-or both? Consumers' Research, 14: 14-17.

Zavestoski, Stephen (2002), The socio-psychological bases of anticonsumption attitudes, Psychology \& Marketing, 19 (2): 149-58. 